\title{
1964 meio século depois
}

José Murilo de Carvalho

\section{Prólogo mineiro.}

O professor João Antônio de Paula não faz ideia da satisfação que me proporcionou ao fazer o convite para falar nesta ocasião de balanço da gestão do Reitor Clélio Campolina Diniz e de sua equipe. A razão da alegria é o fato de ser a UFMG minha alma mater: aqui me formei e aqui ensinei durante nove anos. Mais precisamente, a Faculdade de Ciências Econômicas é minha alma mater, o que torna mais significativa para mim esta ocasião pois o reitor Campolina é professor da Face e a dirigiu por oito anos, infelizmente depois que eu já partira.

Permitam-me breve reminiscência. Frequentei a FACE entre 1962 e 1965. Guardo da época lembranças muito positivas. A FACE funcionava! Os professores ensinavam, os alunos estudavam, os servidores técnico-administrativos executavam com competência suas tarefas. Para o Brasil, e talvez mesmo para a UFMG, era um espanto! Graças à iniciativa de um déspota esclarecido, o antigo dire- por uma rebelião de alunos, a FACE dispunha, como é sabido de todos, de um original sistema de bolsa para alunos de graduação, precursor da atual bolsa de Iniciação Científica, que teve resultados magníficos. Muitos ex-bolsistas, economistas e sociólogos, atingiram projeção nacional, com as exceções de costume, como a de quem vos fala. Em minha época, os bolsistas ficavam trancados em um andar com obrigação de ajudar os colegas e escrever uma monografia cada ano. Meu primeiro artigo publicado, e o foi em 1966 na Revista Brasileira de Estudos Políticos, de Orlando Carvalho, originou-se de uma dessas monografias.

Eram tempos agitados, de intensa atividade política, em que a FACE era referência nacional, tendo lá estudado o presidente da UNE. Mas lá a política não afastava os alunos da sala de aula. Quem quisesse exercer liderança estudantil, na Ação Popular, no Partido Comunista, ou na Polop, tinha que estar entre os primeiros na sala de au- 
la e vincular a ação com o que aprendia nos livros. Mesmo assim, nem todos simpatizavam com a ação política. Os alunos de Economia e Administração de Empresas não se sentiam à vontade na companhia dos de Sociologia e Política que consideravam agitadores que prejudicavam suas carreiras. Isso não os impedia, naturalmente, de namorar nossas colegas, aproveitando-se do fato de que no mercado matrimonial da época os economistas eram mais competitivos do que os sociólogos que, mesmo assim, acabaram sendo exportados, juntamente com as sociólogas, para a FAFICH, felizmente para mim só depois que saí de lá.

Entre vários excelentes professores da FACE, tive o privilégio de ser aluno de Francisco Iglésias, ícone da historiografia mineira, um historiador que fazia a história dialogar com a economia, com a literatura, com as artes, com o cinema. Fui ainda aluno de outro professor menos cultuado mas não menos inspirador, Júlio Barbosa. Foi ele o responsável pela edição, na Faculdade, da Revista Brasileira de Ciências Sociais, que rivalizava com a Revista Brasileira de Ciência Política que Orlando de Carvalho editava na Faculdade de Direito. As duas, em consonância com seus títulos, eram referência nacional e mesmo internacional, e até hoje não foram igualadas.

A marca da universalidade, a meu ver, e talvez na contramão do senso comum, é inerente ao melhor espírito mineiro. Nossa universalidade estava no barroco (folclore mineiro é latim, dizia o senador Afonso Arinos), no Caraça que educou boa parte da elite política mineira, na Escola de Minas, que formou nossos primeiros engenheiros de minas e civis, em Teófilo Otoni que plantou no vale do Mucuri uma cidade chamada Filadélfia, nos modernistas mineiros. Pelo que me informaram, aliás, a UFMG está perseguindo esta trilha de universalismo e já iniciou mesmo o ensino do mandarim. Creio que os mineiros não terão dificuldade em aprender essa língua por sua proximidade fonética com nosso dialeto: mandarim, shaolim, trenzim, tiquim, inhotim. Piada de mineiro é muito bom, ela nos diverte e diverte os outros. Mas ela também nos confina em um nicho paroquial que é empobrecedor. Foi dentro, desse espírito universalista que o Reitor Campolina,-- e quem mais mineiro do que ele?-- citou em seu discurso de posse um verso do maior de nossos modernistas, o universal Carlos Drummond de Andrade: "Tenho apenas duas mãos e o sentimento do mundo". Acrescento outro verso famoso de Drummond: "Mundo, mundo, vasto mundo/mais vasto é meu coração". E complemento com Milton Nascimento, outro mineiro universal, que cantou: "Sou do mundo, sou Minas Gerais".

\section{4}

Mas chega de nostalgias, que tenho trabalho a fazer. O professor João Antônio não pagou minha passagem ex abundantia cordis, embora esta não lhe falte. Deu-me tarefa: falar sobre o Brasil de hoje. Para sorte minha, que, por vício profissional, gosto de ver as coisas em perspectiva, $o$ hoje, 2014, é marcado por duas importantes efemérides, os 50 anos do golpe de 64 e os 30 anos da campanha das diretas. Assim posso voltar aos anos 60 e 70 de meus tempos de UFMG, embora este exercício seja um tanto constrangedor pois me dou conta de que biografia já começa a se confundir com história. Falarei, então, sobre os 50 anos do golpe de 1964 e do sentido que teve para o percurso de nossa democracia. Para antecipar críticas, advirto que a ênfase que será dada à dimensão política não visa provocar os antigos colegas da FACE da área de Economia. Justifico minha posição com uma citação de um economista de reconhecida autoridade, Mário Henrique Simonsen. Por ocasião do trigésimo aniversário do golpe de 1964, convidei-o para falar sobre a dimensão econômica do movimento em mesa 
redonda realizada na Fundação Getúlio Vargas. Ele nada falou sobre economia. Cobrei dele o silêncio e sua resposta surpreendeu a todos: "O golpe de 1964 nada teve a ver com economia, foi só política”. Vamos, então, à política, sob as bênçãos de Simonsen.

Em 31 de março 1964, em Juiz de Fora, o general Olímpio Mourão Filho pôs em marcha as tropas da IV Região Militar em direção ao Rio de Janeiro, disparando o movimento que depôs o presidente João Goulart. Infelizmente, a iniciativa veio de Minas e de um general mineiro, ex integralista e que se autodefinia como uma vaca fardada.

Foi seguramente um golpe civil-militar por conta do amplo apoio civil, de governadores, inclusive o de Minas Gerais, Magalhães Pinto, de senadores, deputados, empresários, da Igreja, da maior parte da imprensa e da população que foi às ruas em grandes passeatas, sobretudo em São Paulo e no Rio de Janeiro. Aqui em Belo Horizonte, lembro-me de um comício de Leonel Brizola que, como a batalha de Itararé no verso de Murilo Mendes, não houve. Os alunos da FACE batalhamos contra a cavalaria da Polícia Militar tentando viabilizar o evento marcado para se realizar no amplo auditório da Secretaria de Saúde, então localizada em prédio ao lado do mercado central. Quando entramos no salão, a mesa já estava tomada por mulheres frenéticas que agitavam terços e rezavam ave-marias em defesa de Deus, pátria e família. Brizola não passou do saguão. Voltando a Drummond, "no meio do caminho tinha um terço/ tinha um terço no meio do caminho". "Nunca me esquecerei desse acontecimento".

A vitória fácil surpreendeu a todos, golpistas e golpeados. Do lado golpista, nem mesmo foi necessária a ajuda de Tio Sam; do lado golpeado, evaporaram-se todos os dispositivos militares, sindicais, estudantis, sumiram os Grupos dos Onze de Brizola. No dia primeiro de abril, vagávamos perplexos pela avenida Afonso Pena, cuidando apenas em não sermos encontrados por algum dos colegas direitistas que andavam armados pelas ruas caçando subversivos.

Em perspectiva nacional, o golpe encerrou o experimento democrático iniciado em 1945, quando as Forças Armadas depuseram Getúlio Vargas. A partir daquele momento, nossa República oligárquica que elegia presidentes com participação eleitoral de $5 \%$ da população, começou a ser invadida pelo povo nas urnas e nas ruas. Graças à expansão da franquia eleitoral, então iniciada, forças políticas, aí incluídos os partidos, começaram a se mobilizar em torno de grandes temas, como o imperialismo, o comunismo, o nacionalismo, representado pela luta pelo petróleo, as reformas de base. O sistema político logo começou a dar sinais de que não suportaria pressão tão grande e tão nova. Sobrevieram vários solavancos, como o suicídio de Vargas em 1954, sob pressão militar e udenista, o golpe preventivo de 1955 dado pelo marechal Lott para garantir a posse de Juscelino Kubitscheck, as revoltas de Aragarças e Jacareacanga, a crise da posse de João Goulart em 1961. De um lado, pressão por reformas vinda de entidades sindicais, e estudantis, ligas camponesas e setores modernos da classe média; do outro, medo das reformas vindo do empresariado urbano e rural, das Forças Armadas, de grupos religiosos. Tudo isso temperado e agravado pela histeria anticomunista gerada no bojo da Guerra Fria.

A partir da crise de 1961, os acontecimentos precipitaram-se. Entrou-se numa dinâmica que alguém na época chamou de política do sobressalto. Era um acabar nunca de greves, protestos, passeatas, marchas com Deus pela Família e pela Pátria, revoltas de sargentos e marinheiros, manifestos de governadores e generais. Fazendeiros armavam-se contra os projetos de reforma agrária. Brizola pedia o fechamento do Congresso e criava o grupo dos Onze. Setores militares tramavam a queda de Goulart. Todos se diziam democratas e acusavam os adversários de golpistas. 
A política escapava dos fóruns institucionais de debate e saía para as ruas das cidades, para o campo, para os sindicatos, para as universidades, para aos quartéis, para a imprensa e entrava em uma dinâmica de radicalização e polarização incontrolável. O golpe de 1964 foi a culminação de tudo isso.

No entanto, pesquisas do Ibope na época indicavam a vitória de JK nas eleições marcadas para 1965, isto é, mostravam que a radicalização não abrangia o grosso da população que, no grosso, se mantinha moderada e centrista. Isto nos levar a pensar que o golpe não foi produto de necessidade histórica. Ele se deu, e aqui Simonsen pode ter razão, por razões políticas, pelo comportamento de atores políticos, movidos mais por paixões do que por cálculos racionais. Mas isto, afinal, é a política. O sistema entrou em colapso e fez naufragar o experimento democrático iniciado em 1945.

\section{Ditadura e novo esforço democrático.}

O golpe, e a ditadura de 21 anos que se seguiu, tiveram trajetória complexa. O eclipse democrático foi parcial até 1968, ano do famigerado AI-5, total até 1979, ano da anistia, e novamente parcial até 1985, quando o sol da liberdade brilhou de novo nos céus da pátria, conjurado em boa parte pelo belo espetáculo democrático das Diretas Já, em que muitos de nós tomamos parte. A partir de 1985 até os dias de hoje foram 29 anos de bom tempo, com trovoadas esporádicas, sobretudo na primeira década até a introdução do plano Real, um dos raros acertos dos economistas, alguns deles ex-alunos da FACE.

Os brasileiros testemunharam nesses 50 anos o surgimento de um país novo, quase irreconhecível. Os 70 milhões de habitantes de 1960 quase triplicaram nos 200 milhões de hoje. A população urbana quintuplicou de 31 milhões para 160 milhões, gerando um país mais urbanizado do que os
Estados Unidos. A expectativa de vida passou de 48 para 75 anos, um ganho de 27 anos. Os 15,5 milhões de eleitores de 1960 octuplicaram para 132 milhões em 2010, 70\% da população. A população universitária, que era de pouco mais de 100 mil, saltou para sete milhões. A lista das mudanças drásticas poderia alongar-se. Baste esta amostra.

Em consonância com a perspectiva aqui adotada, vou concentrar meus comentários na dimensão política, mais precisamente, nas vicissitudes da democracia, isto é, no percurso seguido por ela até hoje, quase 30 anos depois do segundo recomeço de 1985. Buscarei responder, de modo muito sintético, a três perguntas: o que herdamos da ditadura; o que acrescentamos na fase democrática; o que nos falta alcançar?

O que herdamos? Pelo lado negativo, herdamos 21 anos sem prática democrática, sem liberdade de imprensa e de organização, sem garantias de direitos civis, inclusive de integridade física e de vida, de direitos políticos de voto livre e de eleições diretas; herdamos 50 milhões de eleitores que começaram a votar, quando o voto não fazia sentido, quando o Congresso tinha seus poderes castrados e era sujeito a recessos forçados, quando os representantes viviam sob ameaça de cassação de mandatos e perda de direitos políticos, 50 milhões de eleitores a quem escapava o sentido cívico do ato de votar; herdamos uma elite política formada em tempos de arbítrio e por isso mesmo oportunista e desfibrada. Pelo lado positivo, a crueza da ditadura levou os dois lados que se digladiavam em 1964 a um mea culpa pelas atitudes polarizadas então adotadas, e à adoção de nova postura favorável ao diálogo e à democracia; herdamos um novo povo político, forjado nas grandes manifestações das Diretas Já (1983-84), quando mais de 4,5 milhões de pessoas acorreram às ruas de dezenas de cidades, revelando um povo agora unido e politizado, mas despolarizado tendo à frente artistas e antigos democra- 
tas sobreviventes da ditadura, como Ulisses Guimarães e Tancredo Neves, a quem se juntavam alguns novos como Fernando Henrique Cardoso e Luís Inácio da Silva. Em Belo Horizonte, 400 mil pessoas desfilaram em 24 de fevereiro de 1984. Eu estava na passeata de um milhão de pessoas no Rio de Janeiro em 10 de abril.

O que acrescentamos? Muito. Acrescentamos 30 anos de prática democrática ininterrupta, com liberdade de imprensa e de organização; a rotinização da substituição de governantes, com transmissões regulares e civilizadas do poder, sem as tradicionais contestações de antes de 1964; acrescentamos o espetáculo único de um impeachment de presidente reclamado pacificamente por milhões nas ruas e sancionado pelo Congresso; acrescentamos a estabilização da moeda que interrompeu uma sequência infernal de surtos inflacionários que nos atormentava desde a década de 1960, agravando as crises políticas; acrescentamos a inclusão social de milhões de brasileiros marginalizados pela pobreza. Acrescentamos, em suma, a capacidade de disputar o poder e promover reformas dentro das regras do jogo democrático. Nossa República, depois de cem anos, conseguiu, afinal, absorver o povo sem entrar em colapso, tornou-se democrática.

O que nos falta? O percurso em direção a uma república democrática estável não está completo, se é que pode estar em algum momento. Viemos de longe, mais longe temos que ir. Falta-nos, antes de tudo, acertar as contas com o próprio golpe e, sobretudo, com a ditadura que se seguiu. Os estudos sobre transição de ditaduras para democracias distinguem três fases, a da indenização, a da verdade e a da justiça. Passamos apenas pela primeira fase. A luta pelo estabelecimento da verdade ainda continua, sem grande probabilidade de êxito. A fase da justiça talvez nunca seja atingida. Estamos longe do que conseguiram países do Cone Sul que também passaram por governos ditatoriais.
Se não chegarmos pelo menos à verdade, só possível com acesso amplo à documentação do período, esta página de nossa história ficará aberta expondo as dores de todas as vítimas da violência do Estado.

Houve grande redução da pobreza, mas nossa desigualdade ainda é das maiores do mundo. Igualdade e liberdade sempre estiveram em conflito ao longo da história, mas nos tempos de hoje uma não pode ser plena sem a outra, e isto pela simples razão de que a desigualdade é também uma forma de restrição da liberdade na medida em que é privação de recursos necessários para seu exercício eficaz. O cidadão, mesmo que livre da pobreza, não poderá exercer com plenitude sua cidadania se estiver preso ao mundo da necessidade, como ainda estão milhões de brasileiros, inclusive aqueles beneficiados pelos programas de erradicação da pobreza que se tornaram clientes do Estado, transformado em Grande Coronel.

Outra condição para o pleno exercício da liberdade e para a formação de cidadãos capazes de atuação independente --independente inclusive das benesses do governo-é a universalização com qualidade do ensino médio. Nossa escolaridade ainda é baixíssima e damos vexame nos indicadores internacionais de qualidade de aprendizado. Falta-nos também ainda avançar no processo de republicanizar nosso regime republicano no sentido de introduzir nele práticas de bom governo, voltadas para a gerência eficaz e honesta dos recursos públicos no atendimento das demandas nos campos da saúde, educação, mobilidade urbana, segurança pessoal. O julgamento do mensalão, seguido da condenação dos réus, representou grande avanço no sentido de quebrar nossa tradição de impunidade de poderosos. Mas, para que o efeito seja duradouro, é necessário que haja continuidade nessa nova postura assumida pela Suprema Corte e uma reforma generalizada em nosso sistema judicial e policial. 
Sobretudo, é necessário reformar o sistema representativo para lhe devolver a credibilidade que ele claramente perdeu. Mais ainda que reformar, é necessário institucionalizar novos canais de representação para atender a novas demandas e a novas tecnologias de comunicação. Já antes das manifestações de junho do ano passado, pesquisas de opinião pública indicavam baixíssima confiança dos cidadãos nas instituições representativas e em seus agentes. Nessas pesquisas, a confiança demonstrada no Congresso e nos políticos raramente saía da casa dos $20 \%$. Nas manifestações de junho, o fenômeno escancarou-se. Diferentemente de todas as manifestações de massa anteriores, as de 1964, as da Diretas Já e a do impeachment, as multidões que foram às ruas em junho, compostas sobretudo de jovens, demonstraram desconfiança e repúdio de políticos e mesmo da política. A grande surpresa causada pelo fenômeno, cujas repercussões ainda não se podem bem avaliar, e as várias interpretações que se lhe podem dar, não devem desviar a atenção do ponto central: por que, apesar de uma situação econômica e social aparentemente positiva, apesar de toda a propaganda oficial em louvor de um governo que se dizia popular, por que, apesar de tudo isso, surgiu tão clara demonstração de insatisfação e de rejeição de políticos e da política? Como no reino da Dinamarca, há algo podre em nossa democracia.

Trata-se, claramente, de sintoma de que nossa democracia ainda não está madura, de que um novo tipo de cidadão, um novo tipo de povo político podem estar surgindo, com novas demandas e novos recursos de atuação baseados nas redes sociais. Esse novo povo político pode ser mesmo produto das políticas de inclusão social e de aumento de renda. Seria uma consequência lógica, embora não prevista: novos recursos, novas demandas; quanto mais novos recursos, tanto mais novas demandas. É a história em movimento exigindo que a sociedade, para manter e consolidar a democracia, acompanhe a dinâmica dos tempos.

\section{Gerações.}

Termino. Minha geração, a que viveu 1964, tropeçou no início mas acabou passando à geração de 85 um país reposto no caminho democrático. É tarefa da geração de 85 repassar à de 2014 uma democracia e uma república consolidadas. Nesse esforço, a UFMG, e as universidades em geral, têm papel importante a cumprir. É um papel que se refere certamente, e em primeiro lugar, ao Brasil e à construção entre nós de uma república democrática. Mas ele vai além de nossas fronteiras porque o estado do mundo afeta cada vez mais nosso estado, inclusive o estado de nossa democracia. Fronteiras quase não há mais. A tarefa que se coloca é enfrentar o desafio de decifrar e ajudar a construir o admirável mundo novo que está surgindo, grávido de grandes promessas e de grandes riscos. Tenho certeza de que a UFMG continuará, e mesmo reforçará, seu compromissocom o cumprimento dessa tarefa nacional, universal e humana. Universalismo e humanismo, com disse no início, são partes da herança mineira. Somos Minas Gerais, somos do mundo.

Obrigado. 